\title{
PROFESSORES DO ENSINO FUNDAMENTAL E CONCEPÇÕES DE LINGUAGEM: POR UMA PERSPECTIVA DIALÓGICA
}

\author{
Fabiana Goes da Silva Agostinho ${ }^{1}$, Ana Luzia Videira Parisotto ${ }^{2}$ \\ Universidade Estadual Paulista Júlio Mesquita Filho - UNESP, Departamento de Educação, Presidente Prudente, SP.. E- \\ mail: fabigoessc@hotmail.com.
}

\section{RESUMO}

O trabalho docente é guiado por suas escolhas metodológicas que, por sua vez, são indícios de suas concepções. Neste artigo, apresentamos um recorte de uma pesquisa de mestrado, de base qualitativa, que contou com a participação de cento e cinquenta e oito professores de vinte e duas escolas do município de Presidente Prudente/SP. Os dados foram analisados à luz da análise de conteúdo e do referencial teórico voltado para concepção dialógica de linguagem. O objetivo deste artigo é compreender e analisar quais são as concepções de linguagem apresentadas pelos professores sujeitos da pesquisa. Observamos que os professores conceituam linguagem de forma monológica.

Palavras-chave: Concepções docentes, linguagem, ensino de língua materna, produção de texto, pesquisa qualitativa.

\section{ELEMENTARY TEACHERS AND LANGUAGE CONCEPTIONS: for one dialogic perspective}

\begin{abstract}
Teaching work is guided by their methodological choices which, in turn, are indicative of their conceptions. In this article, we present a cut of a qualitative master's research that included the participation of one hundred and fifty eight teachers from twenty two schools in the municipality of Presidente Prudente / SP. The data were analyzed in the light of the content analysis and the theoretical reference aimed at the dialogical conception of language. The purpose of this article is to understand and analyze the conceptions of language presented by the subject teachers of the research. We observed that teachers conceptualize language in a monological way.

Keywords: Teachers conceptions, language, teaching mother tongue, text production, qualitative research.
\end{abstract}




\section{INTRODUÇÃO}

Para compreender melhor as escolhas metodológicas dos professores, acreditamos que seja necessário analisar e conhecer suas concepções, pois, para todas as escolhas que fazemos, precisamos recorrer às nossas bases, sejam elas teóricas ou metodológicas. No entanto, em grande parte do tempo, agimos instintivamente e não avaliamos o que nos motiva em nossas decisões. Os professores vivenciam isso diariamente, a falta de tempo e a demanda de tarefas dificulta a análise e reflexão sobre seus atos. Dessa forma, muitas vezes, desconhecem suas próprias concepções. Segundo Weisz (2001, p.55),

Quando analisamos a prática pedagógica de qualquer professor vemos que por trás de suas ações, há sempre um conjunto de ideias que as orienta. Mesmo quando ele não tem consciência dessas ideias, dessas concepções, dessas teorias, elas estão presentes.

Para Antunes (2009, p.34),

A complexidade do processo pedagógico impõe, na verdade, o cuidado em se prever e se avaliar, reiteradamente, concepções (O que é a linguagem? O que é uma língua?), objetivos (Para que ensinamos? Com que finalidade?), procedimentos (Como ensinamos?) e resultados (O que temos conseguido?), de forma que todas as ações se orientem para um ponto comum e relevante: conseguir ampliar as competências comunicativointeracionais dos alunos.

De acordo com Travaglia (2009), o modo como o professor sistematiza seu trabalho com a língua materna está ligado à maneira com que ele concebe a linguagem e a língua.

A linguagem é condição sine qua non na apreensão e formação de conceitos que permitem aos sujeitos compreender o mundo e nele agir; ela é ainda a mais usual forma de encontro, desencontro e confronto de posições porque é através dela que estas posições se tornam públicas. Por isso é crucial dar à linguagem o relevo que de fato tem: não se trata evidentemente de confinar a questão educacional à linguagem, mas trata-se da necessidade de pensá-la à luz da linguagem. (GERALDI, 2010, p. 34).

São três as concepções de linguagem possíveis: linguagem como expressão do pensamento, como instrumento de comunicação ou como forma de interação. As duas primeiras concepções trazem uma perspectiva monológica, enquanto a terceira indica uma visão dialógica.

A linguagem como expressão do pensamento é a primeira das concepções de linguagem reconhecidas. Nela, a linguagem é construída interiormente e para ser exteriorizada é preciso organização lógica do pensamento, para tanto necessita-se de conhecimento das regras gramaticais para adequá-la. Nesta concepção "a enunciação é um ato monológico individual, que não é afetado pelo outro nem pelas circunstâncias que constituem a situação social em que a enunciação acontece." (TRAVAGLIA, 2009, p. 21).

A concepção de linguagem como instrumento de comunicação, segundo Travaglia (2009, p. 22), "levou ao estudo da língua enquanto código virtual isolado de sua utilização". A linguagem é transmissão de informação. Para acontecer leva-se em consideração apenas a mensagem, não o interlocutor e a situação de uso. O ouvinte/leitor precisa apenas conhecer o código para decifrar a mensagem, sendo assim, não faz parte da construção e sentidos.

A linguagem como forma de interação se diferencia das duas outras citadas, pois traz uma visão dialógica. Para acontecer é preciso considerar o que se fala, a quem se diz, em que situação e de qual lugar social. Geraldi (2006, p. 41) aponta que "a linguagem é vista como lugar de interação humana [...] com ela o falante age sobre o ouvinte, constituindo compromissos e vínculos que não preexistiam à fala". Em conformidade com Curado (2011, p. 27), "o indivíduo, ao fazer uso da língua, não exterioriza apenas o seu pensamento, nem transmite somente informações; mais do que isso, realiza ações, age, atua, orientado por determinada finalidade, sobre o outro". 
Para compreender melhor o trabalho com produção de textos desenvolvido por professores do ensino fundamental, é necessário estabelecer relações com as concepções por eles apresentadas, no que diz respeito à linguagem.

O objetivo deste artigo é compreender e analisar quais são as concepções de linguagem apresentadas pelos professores sujeitos da pesquisa.

\section{METODOLOGIA}

Os dados foram obtidos por meio da aplicação de questionários a 158 docentes de 22 escolas do município de Presidente Prudente (PARISOTTO,2014). Para este artigo, estabelecemos um recorte, a partir do qual temos como objeto de análise a questão referente às concepções docentes acerca de linguagem.

Para interpretar os dados utilizamos a análise de conteúdo,

Um conjunto de técnicas de análise das comunicações visando obter por procedimentos sistemáticos e objetivos de descrição do conteúdo das mensagens indicadores (quantitativos ou não) que permitam a inferência de conhecimentos relativos às condições de produção|recepção (variáveis inferidas) dessas mensagens. (BARDIN, 2011, p. 48)

Como se tratava de uma questão aberta, dissertativa, as respostas foram analisadas e categorizadas. Para Bardin (2011, p. 43), a análise categorial pretende "tomar em consideração a totalidade de um 'texto' passando-o pelo crivo da classificação e do recenseamento, segundo a frequência de presença (ou de ausência) de itens de sentido". As categorias são como "espécies de gavetas ou rubricas significativas que permitem a classificação de elementos de significação constitutivos da mensagem".

O projeto foi aprovado pelo Comitê de Ética em Pesquisa da Faculdade de Ciências e Tecnologia - Unesp - Presidente Prudente (Protocolo 947.980), em 06/02/2015.

\section{RESULTADOS}

Depois de criadas as categorias, por meio da avaliação das questões, produzimos as tabelas indicando a frequência dessas respostas. Vale lembrar que uma mesma resposta pôde gerar mais de uma categoria. Dessa forma, o número de menções pode não ser equivalente ao número de participantes.

Na tabela a seguir, apontamos as categorias criadas por meio das respostas à questão: "Conceitue linguagem".

Tabela 1. Conceito de linguagem

\begin{tabular}{|ll|} 
Categorias & Frequência \\
\hline Linguagem como expressão do pensamento & 26 \\
\hline Linguagem como forma de comunicação & 57 \\
\hline Linguagem como forma de interação & 4 \\
\hline Modalidades da linguagem & 73 \\
Respostas incoerentes & 6 \\
\hline Não responderam & 13 \\
\hline Total de participantes & 158
\end{tabular}

Fonte: Dados organizados pelas pesquisadoras, 2016. 


\section{DISCUSSÃO}

Percebe-se que as modalidades da linguagem são destaque. São elas: linguagem verbal, não verbal, expressão oral e escrita. Nessas respostas não foi possível identificar a definição de um conceito para o que seja linguagem. Desde esse ponto já observamos um problema significativo: o desconhecimento das concepções de linguagem por parte dos professores, que apenas determinam seus usos.

Ao tomarmos como foco as três concepções apontadas, destaca-se a linguagem como forma de comunicação, seguida da linguagem como expressão do pensamento. O número de professores que indicam a linguagem como forma de interação é irrelevante diante desse cenário.

Dos professores participantes da pesquisa, 83 deixam transparecer em suas respostas a linguagem em uma perspectiva monológica. Apenas 4 demonstram acreditar que a linguagem deva assumir um caráter dialógico. Essas concepções reduzidas de linguagem podem implicar em práticas docentes também superficiais.

A seguir mencionamos alguns exemplos de respostas obtidas por meio do questionário:

Linguagem é a maneira de comunicar algo, podendo ser escrita, oral, etc. (Professor 1linguagem como forma de comunicação).

A forma de expressar nossas opiniões e pensamentos, de nos relacionarmos com o mundo. (Professor 2- linguagem como expressão do pensamento).

Forma de interação social. (Professor 3- linguagem como forma de interação).

A resposta a seguir indica uma passagem entre as três concepções de linguagem.

A linguagem é um importante instrumento de aprendizagem, pois, ao fazer uso dela, podemos expressar nosso pensamento, transmitir informações, realizar ações, agir. (Professor 4).

Nesta última já é possível perceber que o professor compreende que a linguagem é ação, no entanto, não é possível identificar a necessidade do outro para que aconteça.

Asseverar que a linguagem como forma de interação assume perspectiva dialógica, significa afirmar que, em consonância com Bakhtin (2006, p.115) "toda palavra comporta duas faces. Ela é determinada tanto pelo ato de que procede de alguém, como pelo fato de que se dirige a alguém. Ela constitui justamente o produto da interação do locutor e do ouvinte. Toda palavra serve de expressão a um em relação ao outro". A língua não é um produto pronto e acabado, os significados são construídos nas relações, nas interações, sendo assim, necessita do outro para que seja estabelecida. Quem diz, diz algo a alguém em determinada situação.

Para o trabalho com textos em sala de aula e, mais especificamente, o trabalho com a produção textual, o ideal é que a perspectiva da linguagem como forma de interação deve ser assumida. Muito se ouve que os alunos demonstram desinteresse diante dessas atividades, mas podemos pensar que talvez seja insatisfação, haja vista que as propostas de produção textual muitas vezes carecem de informações a respeito do gênero textual e de aspectos discursivos e, nesse sentido, não possibilitam uma real situação de interação verbal.

Segundo Colello (2012, p.154), "a atividade mecânica e as práticas descontextualizadas e pouco significativas, ao invés de promover a reflexão crítica ou a criatividade é uma promoção reducionista do conhecimento, que acaba por fazer surgir uma reação rebelde de descomprometimento."

Essas propostas têm como fundamento o trabalho com a língua como código, que necessita do cumprimento de regras rígidas, por isso direcionado à gramática e à norma culta, frutos de uma perspectiva monológica da linguagem. São as atividades metalinguísticas, que têm como objetivo descrever, categorizar e sistematizar o uso da língua. Ao reconhecer a linguagem numa perspectiva dialógica, o trabalho desenvolvido terá por finalidade a reflexão acerca da língua em seu contexto de uso, isso se materializa em atividades intituladas epilinguísticas. Tais 
atividades são aquelas que tratam dos recursos linguísticos ou aspectos utilizados na interação comunicativa, durante essa interação (TRAVAGLIA, 2009).

Pensar no trabalho com produção de textos requer relembrar que produzir texto é diferente de produzir redação. $O$ uso das redações parte da perspectiva da linguagem de forma monológica, enquanto a produção de textos acontece na interação com o outro, por isso quem produz precisa conhecer seu interlocutor, assim como a situação de interação, para que possa acontecer a construção dos sentidos. Como nas atividades epilinguísticas, a produção de textos deve ser contextualizada e em possíveis situações reais de interação.

Não obstante, o que desperta a nossa atenção é o fato de muitos desses professores nem ao menos indicar um conceito definido de linguagem, o que pode levar a um ensino sem intencionalidade, instintivo, sem objetivos definidos.

\section{CONCLUSÃO}

Para a melhoria do ensino de língua materna, especialmente do que diz respeito ao trabalho com produção de textos, o ideal é que a linguagem fosse concebida numa perspectiva dialógica e que essa perspectiva se tornasse o denominador comum nas ações metodológicas. Mesmo porque, ao utilizarmos a nomenclatura "produção de textos", referimo-nos à construção de sentidos, o que precisa da interação com o outro. A língua não é produto pronto e acabado. 0 texto, atualmente, deve ser trabalhado em sala de aula no intuito de ser interpretado por meio da construção de sentidos, não mais como base apenas para o estudo da gramática. O mesmo podemos dizer sobre o texto produzido pelo aluno.

No entanto, as concepções de linguagem que se destacam dizem respeito a uma perspectiva monológica da linguagem, sendo elas a concepção de linguagem como expressão de pensamento e de linguagem como comunicação. Esse fator pode se refletir em opções metodológicas que não considerem o outro nas ações de linguagem, valorizando assim um trabalho meramente metalinguístico.

\section{REFERÊNCIAS}

ANTUNES, Irandé. Aula de português: encontro e interação. 8. ed. São Paulo: Parábola Editorial, 2009a.

BAKHTIN, Mikhail. Marxismo e filosofia da Linguagem. 12. ed. São Paulo: HUCITEC, 2006.

BARDIN, Lawrence. Análise de conteúdo. Lisboa: Edições 70, 2011.

COLELLO, Sílvia M. Gasparian. A escola que (não) ensina a escrever. 2. ed. São Paulo: Summus, 2012.

CURADO, Odilon Helou Fleury. Linguagem e dialogismo. In: UNIVERSIDADE ESTADUAL PAULISTA. Prograd. Caderno de formação: formação de professores didática geral. São Paulo: Cultura Acadêmica, v. 11, p. 26-33, 2011.

GERALDI, João Wanderley. O texto na sala de aula. 4. ed. São Paulo: Ática, 2006. . A aula como acontecimento. São Carlos: Pedro \& João Editores, 2010.

PARISOTTO, Ana Luzia Videira. A formação do professor dos anos iniciais do ensino fundamental para superação do fracasso escolar: perfil teórico-metodológico e propostas para o ensino de 
língua materna. Projeto de pesquisa financiado pelo CNPQ (Proc. 472024/2014). Presidente Prudente: FCT/UNESP, 2014.

TRAVAGLIA, Luiz Carlos. Gramática e interação: uma proposta para o ensino de gramática. 14. ed. São Paulo: Cortez, 2009.

WEISZ, Telma. O diálogo entre o ensino e a aprendizagem. São Paulo: Ática, 2001. 